\title{
PREPARATION OF THE POPULATION AND HEALTHCARE SYSTEM FOR ACTION IN CASES OF RADIATION ACCIDENT AND NUCLEAR TERRORISM
}

\author{
Jana DJOUNOVA, Ludmil HADJIISKI, and Nina CHOBANOVA
}

\begin{abstract}
Analysis of performed rescue operations during previous nuclear and radiation accidents highlights several problems impacting the quality of emergency response: unsatisfactory preparation of the population and the medical profession for action in extreme circumstances; presence, along with pure radiation damage, of varied spectrum of psychological side effects. According to the authors, in order to reduce the health risk for the affected people, preliminary preparation and training is required. This publication presents a training concept, together with related levels and means of realization.
\end{abstract}

Keywords: Nuclear emergency, protection of the population, specialised emergency teams, training, emergency planning and response.

Accident, by definition, is an unexpected, unpredictable event that could result in individual health damage.

Both nuclear accidents and nuclear terrorism are extraordinary events with low probability of happening. For the period 1944-2001 there were 420 officially registered emergency situations. ${ }^{1}$ According to some authors, ${ }^{2}$ the probability of emergency incidents on a world scale will increase as a result of the continuously increasing use of nuclear power and ionizing radiation sources in the life of people. In case such events occur, the consequences in health, economic, political and psychological aspects will be enormous.

Each nuclear emergency situation by its nature is a unique event with its own genesis, development and consequences. The presence of varied pathology and the enormous flow of victims who must be taken care of within a short period of time raise sharply the problem of the organisation of medical provision. Advance specialisation of cer- 
tain medical establishments is both impossible and economically unreasonable. That is why, the advance planning, preparation and training both of the specialists involved in the emergency response process and of the population in general are of exceptional importance especially for countries with developed nuclear energetics, such as Bulgaria.

Health risks for both operators of IR sources and the population are reduced to the minimum in normal operation of nuclear facilities on the basis of strict radiation control as specified in regulations.

Injuries in case of a large-scale technogenic accident at a NPP, will not be limited within the production site. The population in close proximity and even beyond the country will be affected to a various extent, as the experience in the Chernobyl NPS showed.

The analysis of rescue operations carried out in previous nuclear and radiation incidents (in particular the accident in Goiania, Brazil 1987 and Chernobyl 1986) outlines several major issues affecting the quality of emergency response:

1. The absence or non-observance of the rules for ionizing sources registration, storage and accounting is one of the main causes for emergency situations to arise.

2. The inadequate professional training of both source operators and the medical community is a cause for late detection of accidents, inaccurate initial diagnosing and, hence, the difficult therapy.

3. Besides treatment of ARS, provision of psychological assistance for victims, their relatives and other affected individuals is very important. Quite often, psychosomatic manifestations resulting from an accident last considerably longer than the particular radiation symptoms. ${ }^{3}$

4. The absence of sufficient prior knowledge and skills, and the panic in an emergency situation increases significantly the risk for the life and health of victims.

We would mention a few examples as an illustration. The accident in Goiania, Brazil was as a result of a source containing cesium chloride (50.9 TBq), left behind at an abandoned hospital ward. After destruction of its protection casing, the radiation material was dispersed in the environment, contaminating an area of about $3,000 \mathrm{~m}^{2}$. Contamination spread out very fast due to the high degree of solubility of cesium chloride. The first symptoms of ARS prodromal phase were attributed to a tropical disease. The accident was discovered as late as after two weeks. ${ }^{4}$ Excessive radiation was diagnosed in 250 individuals. ARS was diagnosed in eight of the victims, four died. Radiological monitoring of 112,000 individuals was performed in the process of 
accident management, establishing contamination in 249 of them. A number of psychological effects, as well as increase in the number of psychosomatic disorders, anxiety neurosis, and increase in the number of alcohol and drug abusers were observed. Individuals most affected by excessive radiation became an object of discrimination on behalf of their fellow-citizens who were afraid of further radiation injury. The process of deactivation of the enormous contaminated territory was long and costly. The damages on economy of the entire region were significant.

The Chernobyl accident resulted from gross violation of technological discipline and manufacturing process. 499 individuals suspected of acute radiation syndrome (ARS) were hospitalised during the first days following the accident. 237 of them manifested clinical indications. After a subsequent reassessment of clinical and haematological results, acute radiation syndrome was proved in 134 patients. ${ }^{5}$ The main reason for diagnostic errors was, on one hand, the inadequate competence of medical specialists and, on the other, the fear not to miss the serious diagnosis in the process of examination of a large number of victims over a short period of time. ${ }^{6}$ The initial period of the emergency situation demonstrated absence of preparedness for action of medical services and shortage of medical specialists (doctors, nurses, laboratory technicians) in the regional medical establishments in the initial phase of the accident. Only the leading health establishments were prepared and knew how to act so as to provide high quality treatment within appropriate time periods. Fire-fighters and emergency team members who first got at the place of the accident did not carry dosimeters, and were not subjected to radiometric control for evaluation of the external contamination. An elementary procedure such as change of clothes and taking a bath was not performed within the first 24 hours, which resulted in severe radiation burns. ${ }^{7}$ The measures for overcoming the psychological stress were assessed as ineffective. ${ }^{8}$

The decision not to inform the population and the neighbouring countries even when the assessment of the serious dimensions was already known, was admitted as a mistake. On the contrary, even a decision for complete secrecy was made. ${ }^{9}$ The absence of an objective and timely information addressed to both competent authorities and the population led to inadequate response and created prerequisites for formation of socio-psychological stress. ${ }^{10}$ The absence of any directives on behalf of the central government and the lack of organisation of local responsible factors led to inexcusable delay in the implementation of urgent protection measures (iodine prophylaxis and restriction on the consumption of foodstuffs from contaminated territories). ${ }^{11}$

\section{A Possible Solution}

It is necessary to establish a highly effective national emergency response system in cases of potential or caused nuclear accidents. The system should include: 
- Clear procedures, instructions and algorithms for action;

- Trained medical and non-medical staff;

- Equipment necessary for both radiation and dosimetric control and for medical diagnostics and therapy;

- Pre-planning, as well as decision-making criteria and mechanisms;

- A system for staff training and evaluation of their qualification and ability for quick and accurate response;

- A system for preparation of the population for action in cases of nuclear accidents.

The aim of this publication is to develop a methodology for preparation of the population and specialised teams for action in case of nuclear accident or terrorism.

\section{Material and Methods}

In the research work considered, the authors have analysed the humble experience of Bulgaria in IRS emergency situations, the principal regulations and recommendations of leading international and European organisations (MAAE, EBPATOM, ICRP), and the experience in nuclear accident response exercises conducted in recent years.

A two-part questionnaire form has been developed in order to determine the available resources regarding staff, infrastructure and equipment. The questions in the first part concern primarily characteristics of the medical establishment such as premises, location, and available equipment. The second part contains questions that allow analysing staff preparedness, their knowledge and specific skills for operation in cases of technogenic nuclear accidents.

\section{Results and Discussion}

In a study conducted in 2006 on the preparedness of the population in the Varna region for action in case of a nuclear accident, the authors found lack of knowledge and awareness of the population of personal protection measures to be taken at home. $44.7 \%$ considered themselves not prepared, and $44.8 \%$ evaluated their preparedness as partial. Based on the study conducted, it has been concluded that "preparedness of the population in that region on radiation protection issues is insufficient, which hides potential health and life risks in a real situation." 12

The first results from our study on the preparedness of the healthcare system for action in cases of nuclear accidents and terrorism show that leading medical specialists in their field acknowledge the necessity of additional training in the field of radiation protection. However, similar is the situation in leading countries of the world. In a detailed study conducted in the US, $73 \%$ of the medical establishments participating 
in the study stated they had no preparedness for action and all, without exception, underlined the necessity of additional training and exercise. ${ }^{13}$ A study at British hospitals showed lack of decontamination equipment and protection equipment for emergency medical teams. ${ }^{14}$

In the study considered, the authors propose a training system organised at three levels:

1. General - called by the authors "educational," addressing the population in general;

2. Specific - tailored to the population in the $30 \mathrm{~km}$ zone surrounding a NPP;

3. Specialised - developed for the medical specialists at the Emergency Medical Centre, general practitioners, police departments, fire department, media representatives, etc.

\section{General Level}

At a general level, training should include a system of knowledge that consists of:

- Description and characteristics of ionizing radiations;

- Benefits and damages from the use of sources of ionizing radiation;

- Human health risks and possibilities for protection;

- Brief description of radiation and nuclear accidents in the past; and

- Basic organisation of emergency response, responsible institutions.

All materials should be presented in popular language.

The methods of training may involve several forms:

- Posters, leaflets and folders that are to be distributed in public places, such as general practitioners' rooms, medical centres, hospitals, municipal offices;

- Information bulletins with addresses and phone numbers of responsible institutions;

- Web-pages with appropriate information and on-line training;

- Participation in broadcasts on various media for keeping the population informed;

- Work with media representatives with the intention to create trust in institutions and popularise their activities.

\section{Specific Level}

For training at "specific" level, it is advisable to supplement the general level knowledge with more detailed description of local emergency plans (ways to announce an 
accident, evacuation assembly-points, places for opening of admission and triage wards, etc.) and a national emergency plan.

\section{Specialised Level}

In our opinion, this level should include acquaintance of medical specialists from the healthcare system with the ways to distinguish a radiation injury, the specific behaviour in forming the "Acute Radiation Syndrome" diagnosis, the principles of medical provision, fundamentals of the therapy of a nuclear accident and terrorism victims. The specialised training should involve also representatives of other departments participating in the emergency response (fire department, police, etc.), addressing the issues of personal protection, first aid and mutual aid, personal health risks. It is of particular importance the specialised level to include development of knowledge materials for preliminary training of journalists from leading media, describing to them specific characteristics of radiation injuries and the organisation of medical provision in case of a nuclear accident and terrorism.

To date several materials have been developed at the NCRRP on the benefits and risk from conducting IRS trials in the field of medicine, the radiation risk during pregnancy and in the period of breastfeeding, etc.

NCRRP has its own Web-page for publication of related materials, such as the materials regarding health risks as a result of the accident at the Chernobyl NPS, both for the Bulgarian population and on a world scale.

Specialists from the centre conduct annual courses on "Medical provision in radiation accidents" designated for doctors and other medical specialists from the healthcare system.

Experts from the NCRRP participate in various media programs giving interviews on pressing problems.

The annual "Days of Open Doors" conducted at "Kozloduy" NPP may also be considered as an element of the "educational" training.

There are plans for development of materials addressed to the population concerning personal protection measures that are to be taken in case a nuclear accident is announced; how to take food and water in the early period following the accident, etc.

\section{Conclusion}

The training in the so-called "educational" direction should be conducted regularly in order to achieve a basic level of knowledge in the whole society, to reduce the radiophobia and the distorted notion of the extremely dangerous effect of IRS on the individual's health and generation. Acquiring knowledge of the emergency response sys- 
tem would make it possible in emergency situations the competent authorities to make recommendations quickly and effectively, and, besides, it would be a significant element in the prophylaxis of psychological effects that inevitably accompany each emergency situation. The specialised training of medical specialists will guarantee that a radiation injury is promptly distinguished and adequate measures are taken for diagnosing and immediate admission of the victims at a medical establishment competent to conduct appropriate therapy.

The preparedness of the society for action in case of a nuclear accident and terrorism is a key element in the overall emergency response system, which, in our opinion, should be developed further because, as John Ahearne, Chairman of the U.S. Nuclear Regulatory Commission (1979-1981) said:

"An emergency situation is not the time for decision-making of what should be done during an accident."

\section{Notes:}

${ }^{1}$ International Atomic Energy Agency (IAEA) and World Health Organization (WHO), Training for Radiation Emergency Preparedness and Response: EPR MEDICAL-T (IAEA, Vienna 2002).

2 Richard Agababyan, "Plan for Urgent Medical Response to Radiation Accidents," $<$ www.bumc.bu.edu/www/s.

${ }^{3}$ International Atomic Energy Agency (IAEA), The Radiological Accident in Goiania (Vienna, 1988).

${ }^{4}$ IAEA and WHO, Training for Radiation Emergency Preparedness and Response: EPR MEDICAL-T; Jean-Claude Nénot, "Les accidents d'irradiation 1950-2000. Leçon du passé," Radioprotection 36, no. 4 (2001): 431-450.

5 Angelina K. Guskova, A.E. Baranov, A.V. Barabanova, G.P. Gruzdev, and E.K. Piatkin, "Acute Radiation Effects in Victims of the Accident at the Chernobyl Nuclear Power Station," Journal of Medical Radiology 32, no. 12, (1987): 3-18 (in Russian); Angelina K. Guskova, A.E. Baranov, and A.V. Barabanova, A.A. Moiseev, and E.K. Piatkin, "Diagnosis, Clinical Picture and Treatment of the Acute Radiation Disease in Chernobyl Accident Victims," Therapeutic Archives 61, no. 1 (1989): 95-103.

${ }^{6}$ G.V. Sergeyev, "Medical and Sanitary Measures for the Chernobyl Accident Cleanup" (paper presented at the Medical Aspects of the Chernobyl Accident Scientific Conference, Kyiv, Ukraine, September 1988), 15-26.

${ }^{7}$ Georgi Vassilev and Valentin Angelov, Serious Nuclear Accidents and Emergency Planning Response (Sofia: Tita Consult, 2007), 88-91; Daniel F. Flynn and Ronald E. Goans, "Nuclear Terrorism: Triage and Medical Management of Radiation and Combined-Injury Casualties," Surgical Clinics of North America 86, no. 3 (2006): 601-636.

${ }^{8}$ Executive Summary of the International Conference "Fifteen Years after the Chernobyl Accident. Lessons Learned" held on April 18-20, 2001, Kyiv, Ukraine. 
9 Rudolf M. Alexakhin, L.A. Buldakov, V.A. Gubanov, Ye.G. Drozhko, L.A. Ilyin, I.I. Kryshev, I.I. Linge, G.N. Romanov, M.N. Savkin, and M.M. Saurov, "Large Radiation Accidents: Consequences and Protective Countermeasures," in Twenty Years of the Chernobyl Accident, Results and Problems in Eliminating Its Consequences in Russia 1986-2006, Russian National Report, ed. Leonid A. Ilyin and V.A. Gubanov (Moscow: IzdAt, 2001), $752-757$

${ }^{10}$ Leonid A. Ilyin, ed., Truth and Myth of Chernobyl (Moscow: Alara, 1994), 448-450; Executive Summary of the International Conference "Fifteen Years after the Chernobyl Accident."

${ }^{11}$ Chernobyl, Five Difficult Years: Collection of Materials (Moscow: IzdAt, 1992), 381-382 (in Russian).

${ }^{12}$ Hristina Romanova, "Preparation of the Population from the Varna Region for Protection in Cases of Increased Radiation," Roentgenology \& Radiology 3 (2006): 190-193 (in Bulgarian).

${ }^{13}$ Kimberly N. Treat, Janet M. Williams, Paul M. Furbee, William G. Manley, Floyd K. Russell, and Clarence D. Stamper, "Hospital Preparedness for Weapons of Mass Destruction Incidents: An Initial Assessment," Annals of Emergency Medicine 38, no. 5 (November 2001): $562-565$.

${ }^{14}$ P.J. Saunders and G. Ward, "Decontamination of Chemically Contaminated Casualties: Implications for the Health Service and a Regional Strategy," Pre-hospital Immediate Care 4, 3 (2000): 122-125.

JANA DJOUNOVA received her Masters degree from the Medical Academy of Sofia in 1986. Since 1990 she has been working at the National Centre of Radiobiology and Radiation Protection in Sofia where in 1994 she received her M.Sc. In 1994 she won the International Atomic Energy Agency fellowship award at the IPSN, CEA-Fontenay-aux-Roses, France. Mrs. Djounova has two specialties: in Radiobiology (1994) and in Clinical Laboratory (2003). Now she is head of the department of "Radiation medicine." In the last decade Mrs. Djounova has worked on health monitoring of occupationally exposed persons. Address for correspondence: National Centre of Radiobiology and Radiation Protection, 132 Kliment Ohridski Blvd., 1756 Sofia, Bulgaria; E-mail: jdjounova@ncrrp.org.

LUDMIL HADJIISKI received his Masters degree from the Medical Academy of Sofia in 1960. Since 1965 he has been working in the Military Medical Academy in Sofia, where in 1979 he received his $\mathrm{PhD}$ in Medicine. He became a Professor in Radiobiology in 1990. He works at the National Centre of Radiobiology and Radiation Protection in Sofia since 2002. Prof. Hadjiiski's interests are in the area of radiation hematology and the organization of emergency medical response in cases of radiation accidents.

NINA CHOBANOVA received her Masters degree from the Medical Institute of Varna in 1985. Since 1988 she has worked at the National Centre of Radiobiology and Radiation Protection, Sofia where in 2006 she received her PhD in Medicine. In 1996 she won the International Atomic Energy Agency fellowship award at the European Institute of Oncology, Milan, Italy. Mrs. Chobanova has two specialties: in Radiobiology (1995) and in Radiation Hygiene (2000). Now she is research associate in laboratory "Radiation epidemiology." Mrs. Chobanova's research is centered on assessment of health risk. 